\title{
Duodenal metastasis of breast invasive carcinoma of no special type: a rare presentation
}

\author{
M. Mascarenhas Saraiva ${ }^{1,4}$, T. Ribeiro ${ }^{1,4}$, A.R. Coelho ${ }^{2}$, R. Silva ${ }^{2,3}$, A.C. Real ${ }^{1,4}$, G. Macedo ${ }^{1,3,4}$ \\ (1) Department of Gastroenterology, Centro Hospitalar Universitário de São João, Porto, Portugal ; (2) Department of Pathology, Centro Hospitalar Universitário de São \\ João, Porto, Portugal ; (3) Faculty of Medicine of the University of Porto, Porto, Portugal ; (4) WGO Training Center, Porto, Portugal.
}

\section{To the Editor,}

The authors read with attention the case report by Vande Berg and coworkers, published on a previous issue of this journal, describing a rare diagnosis of rectal metastases of an incognito invasive lobular breast carcinoma (ILC), for which immunohistochemistry was decisive (1). Likewise, we share a similarly rare case of gastrointestinal metastases of breast carcinoma (BC), in which immunohistochemistry played a pivotal role.A 55-year-old woman was diagnosed in June 2015 with an Invasive Breast Carcinoma of no-special-type (IBCNST) grade III, human epidermal growth factor receptor 2 (HER2) positive, estrogen and progesterone receptors (ER/PR) negative. Biopsy revealed vascular permeation. Neoadjuvant chemotherapy and trastuzumab preceded surgery, performed in December 2015, followed by radiotherapy and trastuzumab. The patient remained free of disease until 2017, when a right cerebellar lesion was diagnosed as BC metastasis and was treated with stereotactic radiosurgery. In January 2020, the patient presented with a 1-month history of post-prandial vomiting, epigastric pain, anorexia, fatigue, and a $10 \mathrm{~kg}$ weight loss. Lab tests were unremarkable, except for small increase in CA-125 and CA-15.3. Abdominal CT revealed a contrast-enhancing irregular concentric thickening of the third and fourth duodenal segments (Figure 1 A/B). Upper endoscopy showed an erythematous, highly friable mucosa of the second duodenal segment (Figure 1C), with pleomorphic ulceration. Also, an untraversable stenosis between the second and third duodenal portions was evident (Figure 1D). Biopsies revealed a solid tumor with vascular invasion in the lamina propria. Immunohistochemistry showed GATA3, CK-8/18 and HER2 positive, and ER/PR negative tumor cells, compatible with duodenal BC metastases (Figure 2). A gastrojejunostomy was performed for symptomatic control, which found numerous peritoneal implants. Treatment with docetaxel plus trastuzumab and pertuzumab was started. Six months later, the patient remains asymptomatic.

$\mathrm{BC}$ is the most common cancer affecting women. IBCNST, previously denominated invasive ductal carcinoma, accounts for $75 \%$ of all cases (2). Gastrointestinal metastases are rare and most frequently involve the stomach and colorectum. Clinical and endoscopic presentations

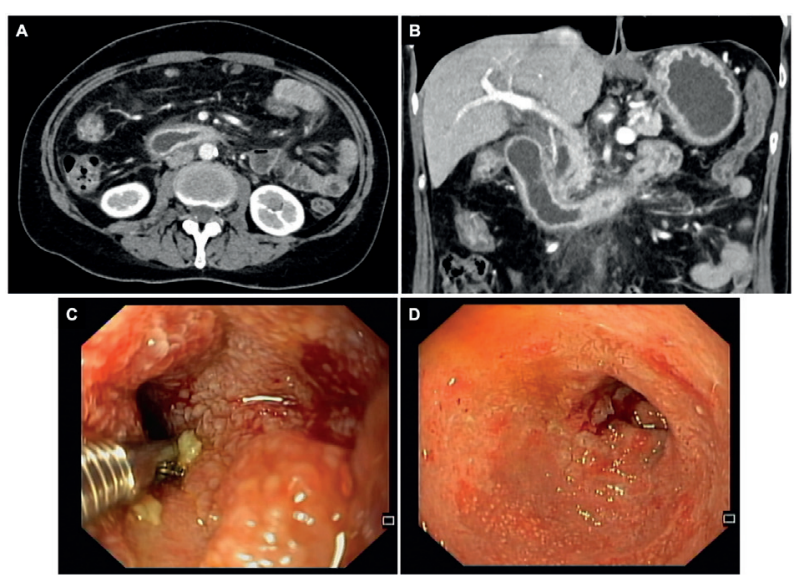

Figure 1. - (A/B) Contrast-enhancing wall thickening of the third duodenal segmen ; (C) upper endoscopy demonstrating congestion, edema and mucosal friability of the second portion of the duodenum ; (D) stenosis of the transition of the second and third portions of the duodenum.

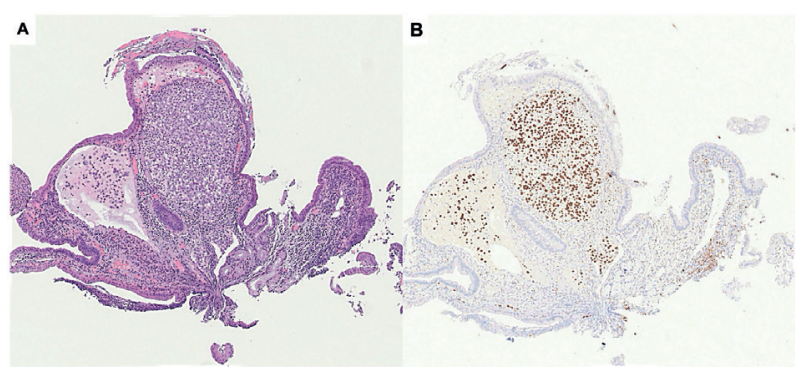

Figure 2. - (A) Neoplastic cells within the lamina propria of the duodenal mucosa (H\&E, 50x) ; (B) Immunohistochemistry (50x) revealing GATA3 expression within the nuclei of neoplastic cells.

are nonspecific. ILC is overrepresented in cases of gastrointestinal metastases (3). Duodenal metastases are exceedingly rare, particularly those of IBC-NST (3).

\section{Conflicts of Interest}

None.

Correspondence to: Miguel José da Quinta e Costa de Mascarenhas Saraiva, Rua Oliveira Martins 104, Porto, 4200-427, Portugal. Phone : 00351912492511. Email : miguelmascarenhassaraiva@gmail.com

Submission date : $18 / 11 / 2020$

Acceptance date : 25/12/2020 


\section{References}

1. VANDE BERG P., FONSECA S., AL-AWA A., REZAI MONFARED M., DELANDE S., CHAMLOU R., et al. A rectal metastasis of an unknown lobular breast carcinoma and its management. Acta Gastroenterol. Belg., 2020, 83(2) : 327-30.
2. GANNON L.M., COTTER M.B., QUINN C.M. The classification of invasive carcinoma of the breast. Expert Rev. Anticancer Ther., 2013, 13(8) : 941-54.

3. MCLEMORE E.C., POCKAJ B.A., REYNOLDS C., GRAY R.J., HERNANDEZ J.L., GRANT C.S., et al. Breast cancer : presentation and intervention in women with gastrointestinal metastasis and carcinomatosis. Ann. Surg. Oncol., 2005, 12(11) : 886-94. 